\title{
Effect of carbon source on electrochemical performance of carbon coated $\mathrm{LiMnPO}_{4}$ cathode
}

\author{
Yuta MIZUNO, Masashi KOTOBUKI, Hirokazu MUNAKATA and Kiyoshi KANAMURA ${ }^{\dagger}$ \\ Department of Applied Chemistry Graduate School of Urban Environmental Sciences, Tokyo Metropolitan University, \\ 1-1, Minami-Ohsawa, Hachioji, Tokyo 192-0397
}

\begin{abstract}
Source materials for carbon coating on $\mathrm{LiMnPO}_{4}$ were examined to improve an electrochemical performance of $\mathrm{LiMnPO}_{4}$. $\mathrm{L}$ ascorbic acid, sucrose, polyethylene oxide (PEO), and carboxymethyl cellulose (CMC) were used as carbon sources for hydrothermal synthesis of carbon coated LiMnPO${ }_{4}$. Disordered (D) and graphite-like (G) carbons were detected by Raman spectroscopy for the prepared samples except for PEO-used one, and the highest G/D ratio was obtained for the sample prepared using CMC as carbon source. The electrochemical performance of the samples was evaluated by galvanostatic charge/discharge test. The carbon coated $\mathrm{LiMnPO}_{4}$ prepared with $\mathrm{CMC}$ carbon source showed the highest discharge capacity, $94 \mathrm{~mA} \mathrm{~h} \mathrm{~g}^{-1}$ at $0.01 \mathrm{C}$ (corresponding to $55 \%$ of the theoretical capacity, $171 \mathrm{~mA} \mathrm{~h} \mathrm{~g}^{-1}$ ), indicating that the carbon sources greatly influenced on the electrochemical performance of the carbon coated $\mathrm{LiMnPO}_{4}$ prepared by the hydrothermal synthesis.
\end{abstract}

(C)2009 The Ceramic Society of Japan. All rights reserved.

Key-words: Carbon-coated $\mathrm{LiMnPO}_{4}$, Carbon sources, Hydrothermal synthesis, Lithium ion battery

[Received September 1, 2009; Accepted October 15, 2009]

\section{Introduction}

$\mathrm{LiMPO}_{4}(\mathrm{M}=$ transition metal) with olivine structure has been attracted as alternative cathode materials for lithium ion batteries owing to their low cost, low toxicity, chemical and thermal stability compared with currently used $\mathrm{LiCoO}_{2}$. Among these compounds, $\mathrm{LiMnPO}_{4}$ is the most attractive due to its high operation voltage determined by $\mathrm{Mn}^{3+} / \mathrm{Mn}^{2+}$ redox couple at $4.1 \mathrm{~V}$ versus $\mathrm{Li}^{+} / \mathrm{Li}$, and is compatible with the system presently used in lithium ion battery. ${ }^{1)}$ However, the most serious problem of this cathode material are low intrinsic electronic and ionic conductivities. ${ }^{2), 3)}$ One of the possible approaches to improve the conductivities is to reduce the $\mathrm{LiMnPO}_{4}$ particle size. ${ }^{4), 5)}$ Drezen et al. reported reversible capacities for 140 and $270 \mathrm{~nm}$ diameter $\mathrm{LiMnPO}_{4}$ particles prepared by sol-gel method were 81 and $7 \mathrm{~mA} \mathrm{~h} \mathrm{~g}$, respectively and increasing particle size of the $\mathrm{LiMnPO}_{4}$ impacted rapidly on reversible capacity. ${ }^{6}$ The most important aspect pointed out by a theoretical report ${ }^{7)}$ that each nano-particle of the active cathode material has contact with both ionically and electronically reservoirs. Various experimental reports have indicated that carbon coating might possess such "mixed conducting" properties. ${ }^{8-10)}$ In fact, we have reported high charge-discharge capacity of carbon coated $\mathrm{LiFePO}_{4}$ synthesized by a hydrothermal method. ${ }^{11)}$ However, most papers have reported only improvement of the electrochemical properties of carbon coated cathode materials. Therefore, a lot of open questions have still remained about effect of carbon coating of the cathode materials, for example correlation between coating morphology and properties of resulting electrode. ${ }^{10)}$

In this paper, we report improvement of the charge and discharge capacities of $\mathrm{LiMnPO}_{4}$ coated with carbon prepared from various carbon sources. Results clearly exhibited that carbon sources affected largely on the cathodic performance of the resulting electrode. From these results, it can be pointed out that

Corresponding author: K. Kanamura; E-mail: kanamura@tmu.ac.jp one of the most important key to obtain the carbon coated cathode with high performance is right choice of the carbon source.

\section{Experimental procedure}

$\mathrm{LiMnPO}_{4}$ was synthesized by a similar hydrothermal process to our previous report for $\mathrm{LiFePO}_{4}{ }^{12)-14)} \mathrm{MnSO}_{4} \cdot 5 \mathrm{H}_{2} \mathrm{O}$ (43.84 g) and $\mathrm{Li}_{3} \mathrm{PO}_{4}(20.84 \mathrm{~g})$ were dissolved into purified water (44 ml) under $\mathrm{N}_{2}$ atmosphere. A molar ratio of Li:Mn:P in the precursor solution was 3:1:1. To prepare carbon coated $\mathrm{LiMnPO}_{4}$, one of various carbon sources $(6.37,6.16,4.76$, and $6.00 \mathrm{~g}$ of $\mathrm{L}$-ascorbic acid, sucrose, polyethylene oxide (PEO), and carboxy methyl cellulose (CMC), respectively) was added into the precursor solution. The precursor solution was put into a glass-lined Parr reactor with $\mathrm{N}_{2}$ gas sealed in a stainless steel autoclave, and then heated at $200^{\circ} \mathrm{C}$ for $3 \mathrm{~h}$ with stirring at $680 \mathrm{rpm}$. A precipitation was produced in the reactor under hydrothermal conditions described above. The precipitation was separated centrifugally at first, and then by a mean of freeze-drying at $-50^{\circ} \mathrm{C}$ for $12 \mathrm{~h}$. Yield was always higher than $95 \%$. In the case of particles prepared with carbon addition, the particles were treated at $700^{\circ} \mathrm{C}$ under $3 \% \mathrm{H}_{2} /$ Ar flow for $1 \mathrm{~h}$ to obtain graphite carbon.

The crystalline phases of the synthesized samples were identified with X-ray diffraction (XRD, RINT-Ultima, Rigaku Co.) with $\mathrm{Cu} \mathrm{K} \alpha$ radiation. Raman measurements (NRS-1000, JASCO Co.) were carried out at room temperature by laser radiation of $532 \mathrm{~nm}$. The morphology of the synthesized particle was observed by a mean of scanning electron microscope (SEM, JSM-6490A, JEOL Ltd.).

A performance of the synthesized $\mathrm{LiMnPO}_{4}$ as a positive electrode was tested by a galvanostatic charge/discharge test. A composite $\mathrm{LiMnPO}_{4}$ electrode was prepared by mixing $\mathrm{LiMnPO}_{4}$, Ketjen black, and Poly vinylidine difluoride (PVdF) in the weight ratio of 75:15:10 in $1.2 \mathrm{ml}$ of NMP (N-methyl pyrrolidone). The $\mathrm{LiMnPO}_{4}$ electrode was painted onto a thin $\mathrm{Al}$ sheet and dried overnight at $85^{\circ} \mathrm{C}$ under reduced pressure for $12 \mathrm{~h}$. The $\mathrm{LiMnPO}_{4}$ electrode (14 mm diameter) was set in a coin 
cell 2032 with a mixture of ethylencarbonate (EC) and Dimethylcarbonate $(\mathrm{DEC})($ volume ratio $=1: 1)$ containing $1 \mathrm{~mol} \cdot \mathrm{dm}^{-3}$ $\mathrm{LiPF}_{6}$ as an electrolyte and with lithium metal as a negative electrode. The galvanostatic charge/discharge tests of the coin cell with the $\mathrm{LiMnPO}_{4}$ positive electrode were performed by using HJ1001SM8A (HOKUTO DENKO CORP.). The measurement was performed under constant current conditions and cut off voltages were $3.0 \mathrm{~V}$ and $4.5 \mathrm{~V}$ for discharge and charge, respectively.

\section{Results and discussion}

\subsection{Bare $\mathrm{LiMnPO}_{4}$ synthesized by hydrothermal process}

At first, $\mathrm{LiMnPO}_{4}$ was synthesized without any addition of carbon sources. Figure 1 shows XRD pattern and Raman spectrum of synthesized $\mathrm{LiMnPO}_{4}$. All of diffraction peaks in the XRD pattern of the synthesized $\mathrm{LiMnPO}_{4}$ (Fig. 1(a)) can be attributed to those of phospho-olivine $\mathrm{LiMnPO}_{4}$ and no impurity phase was detected. The Raman spectroscopy is sensitive to the surface of materials comparing with the XRD. We have succeeded in detection of even small amount of impurity on $\mathrm{LiFePO}_{4}$ synthesized by the hydrothermal process by using a mean of the Raman spectrocopy. ${ }^{14)}$ All of the Raman peaks (Fig. 1(b)) were attributed to $\mathrm{LiMnPO}_{4}$, indicating pure $\mathrm{LiMnPO}_{4}$ was synthesized successfully. The synthesized $\mathrm{LiMnPO}_{4}$ morphology was observed with SEM, as shown in Fig. 2. The SEM image reveals the particle size of the synthesized $\mathrm{LiMnPO}_{4}$ was 200$500 \mathrm{~nm}$ and the morphology of the particles were irregular and agglutinative.

Figure 3 shows the charge and discharge curves of the hydrothermally synthesized $\mathrm{LiMnPO}_{4}$. Results indicated clearly that discharge capacity was very low, only $3 \%$ of the theoretical capacity $\left(171 \mathrm{~mA} \mathrm{~h} \mathrm{~g}^{-1}\right)$, even under low discharge rate, $0.01 \mathrm{C}$. Moreover, the discharge capacity dropped sharply with increase of the discharge rate. The limited capacity may be due to extremely low intrinsic electronic conductivity and slow lithium diffusion kinetics within $\mathrm{LiMnPO}_{4}$ grains. ${ }^{2)}$
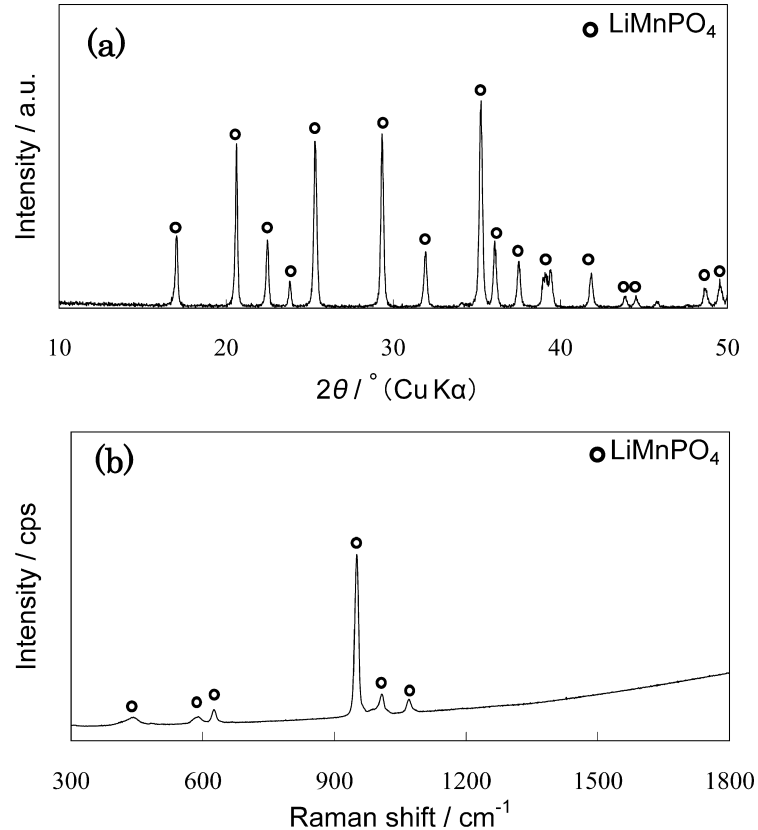

Fig. 1. XRD pattern (a) and Raman spectrum (b) of the synthesized $\mathrm{LiMnPO}_{4}$ without carbon coating.

\subsection{Carbon coated $\mathrm{LiMnPO}_{4}$ synthesized by hydrothermal process}

As mentioned above, the hydrothermally synthesized $\mathrm{LiMnPO}_{4}$ showed very low discharge capacity due to the low electronic conductivity and slow diffusion of lithium in the $\mathrm{LiMnPO}_{4}$ grains. A very efficient way to improve the electronic transport in such materials is supposed to be the preparation of carbon coating layer around the individual active particles. ${ }^{10)}$ To give the electronic conductivity to the $\mathrm{LiMnPO}_{4}$, various carbon sources (L-ascorbic acid, sucrose, polyethylene oxide (PEO), and carboxy methyl cellulose (CMC)) were put into the precursor solution for the $\mathrm{LiMnPO}_{4}$.

XRD patterns of $\mathrm{LiMnPO}_{4}$ prepared with carbon source (Fig. 4(a)) exhibit almost the same diffraction pattern as the bare $\mathrm{LiMnPO}_{4}$ independent of the carbon sources, indicating addition of the carbon sources did not affect on the crystal structure of the $\mathrm{LiMnPO}_{4}$. Any carbon layer was not observed in all XRD patterns. It was found by SEM image (not shown) that the morphology of the $\mathrm{LiMnPO}_{4}$ prepared with carbon source was also almost same as that prepared without the carbon sources, i.e., shape of particles were irregular and agglutinate, and the particle size was 200-500 nm. The Raman spectra of the samples prepared with the carbon sources (Fig. 4(b)) showed a clear peak at $948 \mathrm{~cm}^{-1}$, which attributed to the symmetric vibration of the $\mathrm{PO}_{4}$ group, ${ }^{15)}$ concluding that the addition of carbon sources didn't affect on the olivine structure of the $\mathrm{LiMnPO}_{4}$. A peak at 1610 $\mathrm{cm}^{-1}$ was also observed in Raman spectra of $\mathrm{LiMnPO}_{4}$ prepared with any carbon sources except PEO. This peak was attributed to the $\mathrm{G}$ band (graphite carbon) of Raman vibration mode of carbon. ${ }^{16)}$ Therefore, it can be said that carbon species exist on the

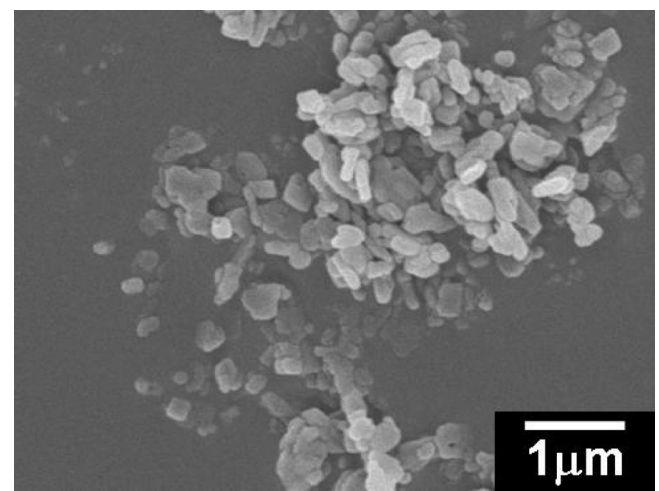

Fig. 2. SEM image of the hydrothemically synthesized $\mathrm{LiMnPO}_{4}$.

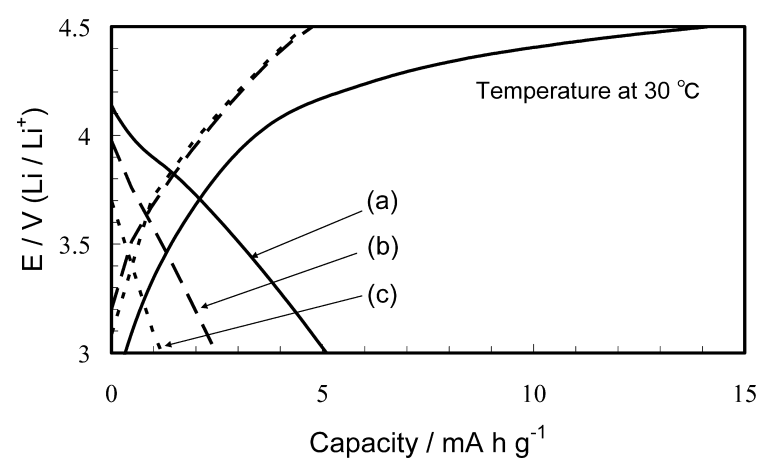

Fig. 3. Charge and discharge curves of hydrothermically synthesized $\mathrm{LiMnPO}_{4}$ at (a) $0.01 \mathrm{C}$, (b) $0.5 \mathrm{C}$ and (c) $0.1 \mathrm{C}$. 

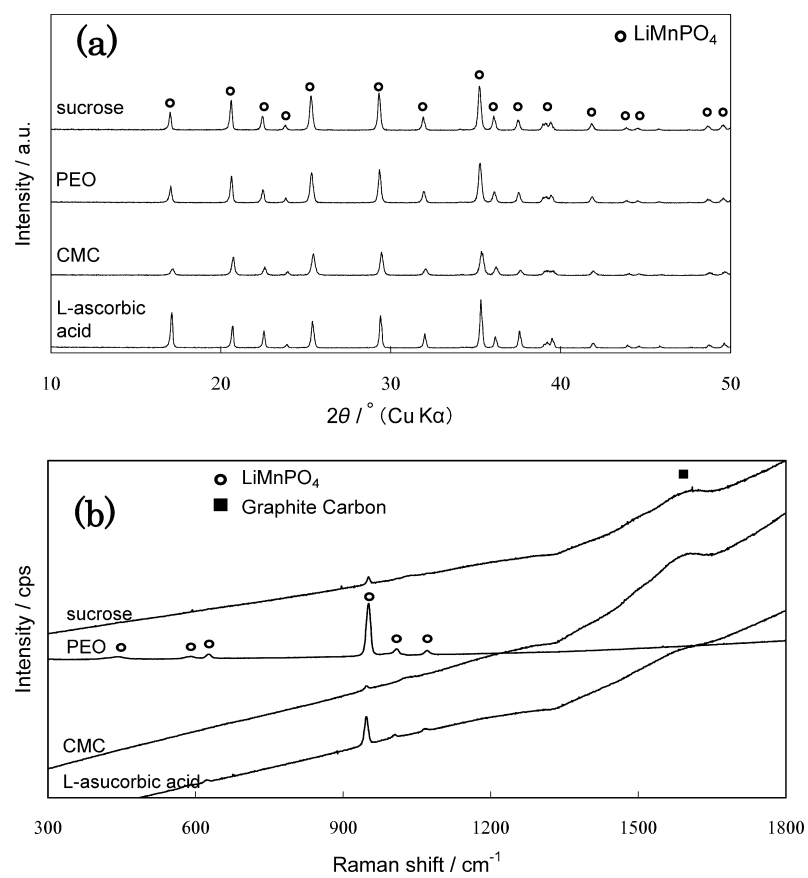

Fig. 4. XRD patterns (a) and Raman spectra (b) of the as-synthesized $\mathrm{LiMnPO}_{4}$ with carbon addition.

surface of $\mathrm{LiMnPO}_{4}$ particles, except PEO carbon source.

In our previous paper, ${ }^{11)}$ we have claimed an optimum temperature for the annealing of hydrothermally synthesized $\mathrm{LiFePO}_{4} /$ $\mathrm{C}$ to increase the electrical conductivity. That was $700^{\circ} \mathrm{C}$. Consequently, the $\mathrm{LiMnPO}_{4}$ hydrothermally synthesized with various carbon sources were annealed at $700^{\circ} \mathrm{C}$ for $1 \mathrm{~h}$ under $3 \% \mathrm{H}_{2} /$ Ar flow.

Figure 5 shows the XRD pattern of the $\mathrm{LiMnPO}_{4} / \mathrm{C}$ after annealing at $700^{\circ} \mathrm{C}$ for $1 \mathrm{~h}$ under $3 \% \mathrm{H}_{2} / \mathrm{Ar}$ flow. All of the diffraction peaks can be attributed to $\mathrm{LiMnPO}_{4}$ olivine structure and no carbon related peaks were observed. However, the Raman spectra were quite different in before and after the annealing. Intensity of the graphite carbon peak increased after the annealing except the case of the carbon source of PEO. This means that graphite carbon film with high electronic conductivity was produced on the surface of the particles during the annealing. It is worth to describe that no difference of the Raman spectra before and after annealing in the case of PEO carbon source. The amounts of coated carbon after annealing were -0.1, 2.4, 2.8 and $5.5 \mathrm{wt} \%$ in PEO, ascorbic acid, CMC, Sucrose, respectively, from TG measurement. The amount of coated carbon in the PEO was within experimental error, meaning the $\mathrm{LiMnPO}_{4}$ was hardly coated by the carbon from the PEO carbon source. Only the PEO doesn't contain hydroxyl group among the carbon sources tested in this study. Therefore, the hydroxyl group would play an important role to make carbon-coated layer on the $\mathrm{LiMnPO}_{4}$ particles. In fact, polystyrene has been used for the carbon source in our previous study and the carbon coated layer on the $\mathrm{LiMnPO}_{4}$ particles could not be created.

In SEM images (Fig. 6), it was found that the morphology of the $\mathrm{LiMnPO}_{4} / \mathrm{C}$ after the annealing was almost the same as the $\mathrm{LiMnPO}_{4}$ without carbon coating, meaning that sintering did not occur. This indicates that the annealing succeeds to make electrical conductive graphite carbon film on the hydrothermally synthesized $\mathrm{LiMnPO}_{4}$ particles without any affect on crystal structure and particle size.
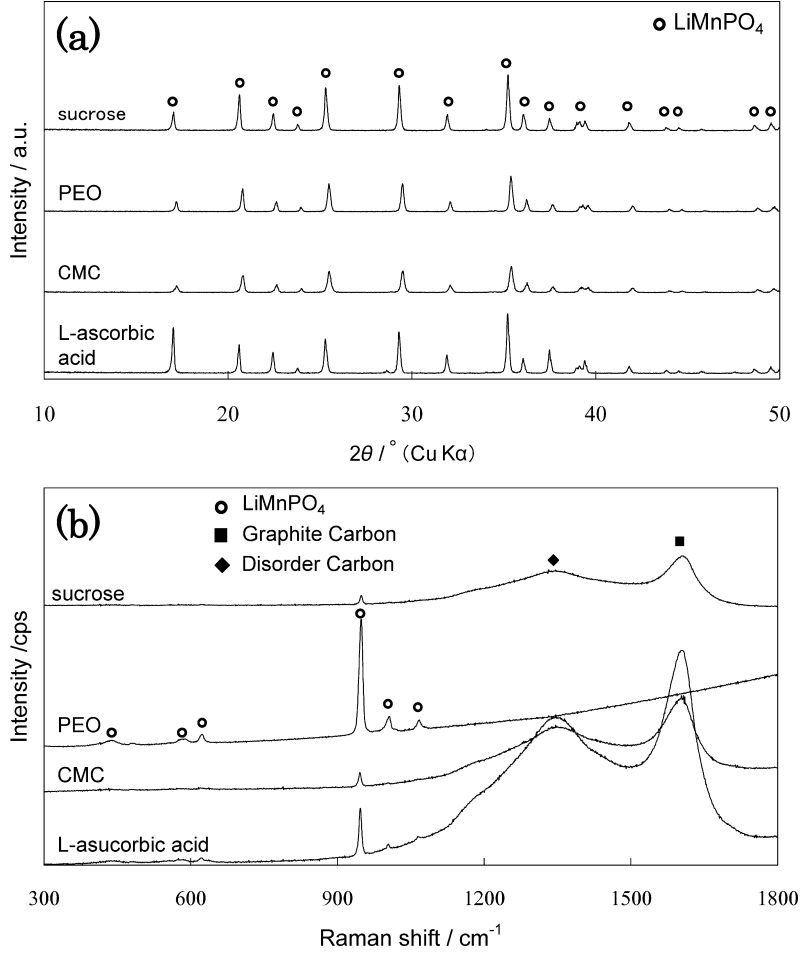

Fig. 5. XRD patterns (a) and Raman spectra (b) of the carbon-coated $\mathrm{LiMnPO}_{4}$ after annealing at $700^{\circ} \mathrm{C}$ under $3 \% \mathrm{H}_{2} / \mathrm{Ar}$ flow.
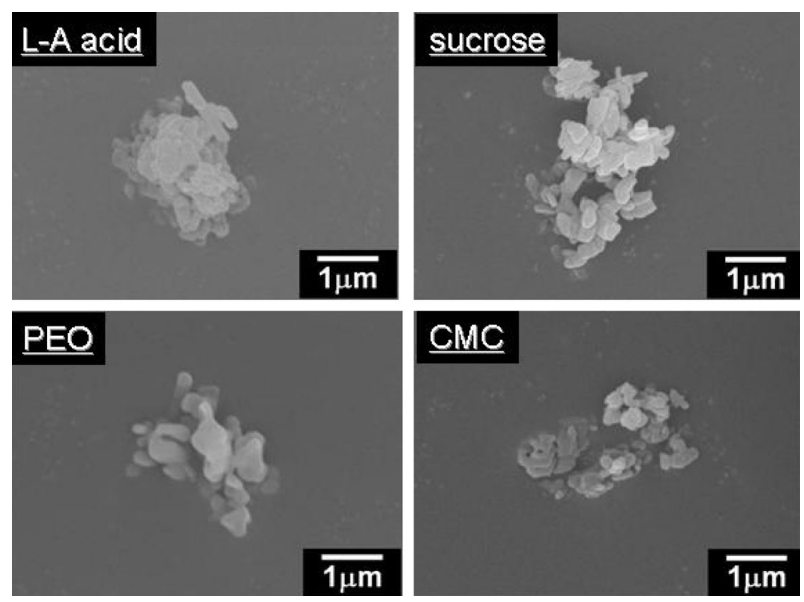

Fig. 6. SEM images of the carbon-coated $\mathrm{LiMnPO}_{4}$ after annealing at $700^{\circ} \mathrm{C}$ under $3 \% \mathrm{H}_{2} / \mathrm{Ar}$ flow.

Figure 7 is the charge and discharge curves of the annealed $\mathrm{LiMnPO}_{4} / \mathrm{C}$ at $0.01 \mathrm{C}$. Improvement of charge and discharge capacities was observed in all samples, even in the case of the PEO carbon source, which coated the $\mathrm{LiMnPO}_{4}$ particles hardly. In the case of the other carbon sources, ascorbic acid, sucrose, and $\mathrm{CMC}$, the charge-discharge capacities were 55, 72, and $94 \mathrm{~mA} \mathrm{~h} \mathrm{~g}{ }^{-1}$, i.e. 32,42 , and $55 \%$ of the theoretical capacity, respectively. It should be remembered that the amount of coated carbon for the best carbon source, CMC, was only half of the sucrose carbon source. This discrepancy would be attributed to kind of carbon species. As shown in the Raman spectrum, there are two kinds of carbon, graphite and disorder carbons, on $\mathrm{LiMnPO}_{4}$. The ratios of the graphite to the disorder carbon estimated from the Raman intensity were $0.773,0.765,0.748$, and 


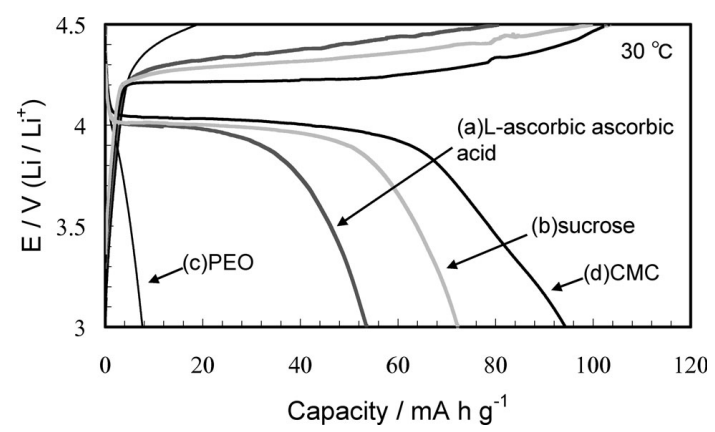

Fig. 7. Charge and discharge curves of $\mathrm{LiMnPO}_{4}$ synthesized with (a) L-ascorbic acid, (b) sucrose, (c) PEO and (d) CMC as a carbon source at $0.01 \mathrm{C}$ after annealing at $700^{\circ} \mathrm{C}$ under $3 \% \mathrm{H}_{2} / \mathrm{Ar}$ flow.

-0.001 in CMC, Sucrose, ascorbic acid, and PEO, respectively, indicating that the $\mathrm{CMC}$ can be converted easily to the graphite carbon with high electronic conductivity. The $\mathrm{LiMnPO}_{4}$ prepared with the sucrose carbon source contained the largest amount of carbon, which was confirmed from the result of the Raman and the TG measurements, but the most of carbon was disorder one, not graphite one. Such a disorder carbon could not provide high electronic conductivity of the carbon coating layer on $\mathrm{LiMnPO}_{4}$. This would be a reason why the $\mathrm{LiMnPO}_{4}$ prepared with the CMC source showed the best performance among the carbon sources used in this research.

In conclusion, the carbon source influences largely on the performance of the carbon coated cathode materials for the lithium ion battery. The best carbon source was CMC in this research, which can coat the cathode material particles readily during the hydrothermal process and can be converted to graphite carbon by annealing. Therefore, carbon source easily graphitized by annealing must be selected to improve cathodic performance of the $\mathrm{LiMnPO}_{4}$.

\section{Summary}

A discharge capacity of hydrothermally synthesized $\mathrm{LiMnPO}_{4}$ was only $3 \%$ of theoretical capacity. To improve the cathodic performance of $\mathrm{LiMnPO}_{4}$, carbon coating was performed by using various carbon sources (L-ascorbic acid, sucrose, polyethylene oxide (PEO), and carboxy methyl cellulose (CMC)). The findings are described below

(1) The PEO can coat the $\mathrm{LiMnPO}_{4}$ hardly. Therefore, the hydroxyl group would play important role to make carbon layer on the $\mathrm{LiMnPO}_{4}$ particles.
(2) The carbon coated $\mathrm{LiMnPO}_{4}$ prepared using CMC as a carbon source showed the highest discharge capacity, $94 \mathrm{~mA} \mathrm{~h} \mathrm{~g}^{-1}$ (corresponding to $55 \%$ of the theoretical capacity, $171 \mathrm{~mA} \mathrm{~h} \mathrm{~g}^{-1}$ ).

(3) Although amount of carbon coat and graphite carbon of the CMC was smaller than that of the sucrose, the prepared $\mathrm{LiMnPO}_{4} / \mathrm{C}$ electrode showed the best performance. A ratio of the graphite to the disorder carbon may be a key to improve the electrochemical performance of the electrode.

Thus, it is suggested that the carbon source can coat $\mathrm{LiMnPO}_{4}$ cathode particles readily and can be converted to graphite carbon by annealing must be selected.

\section{References}

1) H. Fang, L. Li and G. Li, Chem. Phys. Lett., 36, 436-437 (2007).

2) C. Delacourt, L. Laffont, R. Bouchet, C. Wurm, J. B. Leriche, M. Morcrette, J. M. Tarascon and C. Masquelier, J. Electrochem. Soc., 152, A913-A921 (2005).

3) M. Yonemura, A. Yamada, Y. Takei, N. Sonoyama and R. Kanno, J. Electrochem. Soc., 151, A1352-A1356 (2004).

4) A. Yamada, S. C. Chung and K. Hinokuma, J. Electrochem. Soc., 148, A224-A229 (2001).

5) P. P. Prosini, M. Carewska, S. Scaccia, P. Wisniewski and M. Pasquali, Electrochim. Acta., 48, 4205-4211 (2003).

6) T. Drezen, N.-H. Kwon, P. Bowen, I. Teerlinck, M. Isono and I. Exnar, J. Power Source, 174, 949-953 (2007).

7) M. Gaberscek and J. Jamnik, Solid State Ionics, 177, 2647 (2006).

8) Z. H. Chen and J. R. Dahn, J. Electrochem. Soc., 149, A1184 (2002).

9) R. Dominko, M. Bele, M. Gaberscek, M. Remskar, D. Hanzel, S. Pejovnik and J. Jamnik, J. Electrochem. Soc., 152, A607 (2005).

10) J. Moskon, R. Dominko, R. Cerc-Korosec, M. Gaberscek and J. Jamnik, J. Power Source, 174, 683-688 (2007).

11) H. Nakano, K. Dokko, S. Koizumi, H. Tannai and K. Kanamura, J. Electrochem. Soc., 155, A909-A914 (2008).

12) K. Dokko, K. Shiraishi and K. Kanamura, J. Electrochem. Soc., 152, A2199-A2202 (2005).

13) K. Dokko, S. Koizumi and K. Kanamura, Chem. Lett., 35, 338-339 (2006).

14) K. Dokko, S. Koizumi, K. Shiraishi and K. Kanamura, J. Power Source, 165, 656-659 (2007).

15) A. Ait Salah, A. Mauger, K. Zaghib, J. B. Goodenough, N. Ravet, M. Gauthier, F. Gendron and C. M. Julien, J. Electrochem. Soc., 153, A1692-A1701 (2006).

16) R. L. McCreery, in Electroanalytical Chemistry, vol. 17, p. 221. 